\title{
The psychological impact of needlestick injuries
}

\author{
M. B. O'Connor
}

Received: 6 February 2011/Accepted: 24 March 2011/Published online: 1 April 2011

(C) Royal Academy of Medicine in Ireland 2011

\section{Dear Editor,}

We read with great interest the recent publication by O'Sullivan et al. [1] in addition to our research group's recent publication [2], also on needlestick injuries (NIs) among non-consultant hospital doctors (NCHDs) in Ireland. As readers can clearly see from these publications NIs are a major concern among healthcare professionals in Ireland, throughout their working life.

Associated with NIs are a number of knock-on effects. These include an economic burden on the health service and society. Trueman et al. [3] estimated that the annual cost to the NHS of needlestick injuries through insulin administration alone to be $£ 600,000$. This is further supported by Leigh et al. [4] who highlighted that $7 \%$ of NIs in California led to more than 31 days of work being lost. Outside of these direct impacts, litigation is also a burden, as is highlighted by the fact that in 2001 the UK union UNISON made 135 personal injury claims after NIs. In addition to the economic impact of NIs there are psychological impacts. Published research in this area is limited compared to published research describing the minimal physical risk of seroconversion to infection from NIs. Of the limited work in the area of psychological impact of NIs, we would like to draw the readers' attention to the work of Blenkharn and Odd [5]. In their publication of 2008 they noted that out of some 40 NIs among clinical waste handlers there were no seroconversions, but that there were two "prolonged leave of absences due to 'anxiety/stress disorder'". This equates to a possible mental illness risk and prolonged work absence from NIs as 1 in 20.

We acknowledge that data in the area of psychological impact of NIs is limited; however, we would like to highlight that anxiety disorders, adjustment disorders and post-traumatic stress disorders may result from NIs, especially in the period waiting for test results. Hopefully, the coming years will see research into this area and enlighten and educate further.

\section{References}

1. O'Sullivan P, Seoighe DM, Baker JF, O'Daly BJ, McCarthy T, Morris S (2011) Hospital-based needlestick use and injuries by Dublin interns in 2010. Ir J Med Sci; Jan 5 [Epub ahead of print]

2. O'Connor MB, Hannon MJ, Cagney D, Harrington U, O'Brien F, Hardiman N, O'Connor R, Courtney K, O'Connor C (2010) A study of needle stick injuries among non-consultant hospital doctors in Ireland. Ir J Med Sci; Dec 29 [Epub ahead of print]

3. Trueman P, Talyor M, Twena N, Chubb B (2008) The cost of needlestick injuries associated with insulin administration. $\mathrm{Br} \mathrm{J}$ Commun Nurs 13(9):413-417

4. Leigh JP, Wiatrowski WJ, Gillen M, Steenland NK (2008) Characteristics of persons and jobs with needlestick injuries in a national data set. Am J Infect Control 36(6):414-420

5. Blenkharn JI, Odd C (2008) Sharps injuries in healthcare waste handlers. Ann Occup Hyg 52(4):281-286 